\title{
Ensino remoto em sistemas municipais de educação no Brasil: percepções dos gestores escolares
}

\author{
Sanny Silva da Rosa ${ }^{1}$ (c) \\ Angela Maria Martins ${ }^{2}$ (1) \\ ${ }^{1}$ Universidade Municipal de São Caetano do Sul (USCS), Brasil; ${ }^{2}$ Universidade Cidade de São Paulo (Unicid), Brasil
}

Resumo. Este texto apresenta e discute resultados da pesquisa que buscou caracterizar cenários decorrentes das políticas e estratégias adotadas por Sistemas Municipais de Educação no contexto da pandemia de Covid-19 no Brasil. Os dados focalizam, especificamente, as percepções dos gestores escolares acerca dos processos de implementação do ensino remoto e de seus desdobramentos para a organização do trabalho das unidades escolares dos setes municípios que compõem o Grande ABC Paulista, localizado na Região Metropolitana de São Paulo. A metodologia utilizada foi a abordagem não-probabilística, por meio da técnica bola de neve (snowball sampling), que atingiu 501 sujeitos representantes do público-alvo da pesquisa, entre maio e junho de 2020. Os resultados evidenciam a dispersão de iniciativas por parte das secretarias de educação, acarretando consequências graves para os estudantes oriundos dos segmentos mais vulneráveis da população, o que tende a aprofundar as desigualdades sociais e educacionais características da sociedade brasileira.

Palavras-chave: ensino remoto; cenários; sistemas municipais de ensino; gestão escolar; Brasil.

La enseñanza a distancia en los sistemas educativos municipales de Brasil: percepciones de los directores escolares

Resumen. Este texto presenta y discute los resultados de una investigación que buscó caracterizar escenarios resultantes de las políticas y estrategias adoptadas por los Sistemas Educativos Municipales en el contexto de la pandemia Covid-19 en Brasil. Los datos se enfocan especificamente en las percepciones de los administradores escolares sobre los procesos de implementación de la educación a distancia y sus consecuencias para la organización del trabajo de las unidades escolares en los siete municipios que conforman el Gran ABC Paulista, ubicado en la Región Metropolitana de São Paulo. La metodología utilizada fue el enfoque no probabilístico, a través de la técnica de la bola de nieve (snowball sampling), que alcanzó a 501 sujetos representativos del público objetivo de la investigación, entre mayo y junio de 2020. Los resultados muestran la dispersión de las iniciativas de los departamentos de educación, causando graves consecuencias para los estudiantes de los sectores más vulnerables de la población, que tiende a profundizar las desigualdades sociales y educativos característicos de la sociedad brasileña.

Palabras clave: educación a distancia; escenarios; sistemas educativos municipales; gestión escolar; Brasil.

Remote teaching in municipal education systems in Brazil: perceptions of school managers Abstract. This text presents and discusses research results that sought to characterize scenarios arising from the policies and strategies adopted by Municipal Education Systems in the context of the Covid-19 pandemic in Brazil. The data refer specifically to the perceptions of school managers on the implementation processes of remote education and its consequences for the organization of the schoolwork units of seven municipalities that integrate the Greater ABC Paulista, located at Metropolitan Region of São Paulo. The methodology used was the snowball sampling, a non-probabilistic approach which reached 501 subjects, between May and June 2020, representatives of the target audience of this investigation. The results show the dispersion of initiatives by the departments of education, causing serious consequences for students from the most vulnerable segments of the population, which tends to deepen the social and educational inequalities characteristic of Brazilian society.

Keywords: distance education; scenarios; municipal education systems; school management; Brazil. 


\section{Introdução}

Este artigo apresenta parte dos resultados de pesquisa desenvolvida por pesquisadores de três universidades brasileiras ${ }^{1}$ no primeiro semestre de 2020. Os dados se referem à primeira etapa do estudo, cujo objetivo foi caracterizar cenários decorrentes das políticas e estratégias implementadas nos Sistemas Municipais de Ensino do Grande ABC Paulista no contexto da pandemia de Covid-19. O trabalho oferece um panorama da situação vivida nas redes de ensino examinadas a partir da percepção de integrantes das equipes gestoras.

Apesar de números nada otimistas em relação à evolução da pandemia, adentramos o ano de 2021 com alguma esperança, justificada pela celeridade dos avanços científicos em busca da principal arma capaz de combater a maior crise sanitária deste século: as vacinas. Contudo, a ciência tem contra si adversários poderosos, que se caracterizam por posturas de irracionalidade, negacionismo e por ambições de lucro e poder. Desse modo, permanecemos em ambiente incerto que dificulta prever quando, se e como a sociedade brasileira conseguirá vencer esse inimigo invisível.

Nesse contexto, a divulgação de estudos voltados à construção de cenários torna-se relevante na medida em que trazem informações que podem auxiliar no dimensionamento dos problemas a serem enfrentados a curto, médio e longo prazos, em decorrência da pandemia. No que tange à educação e, especificamente, ao ensino público, os efeitos do longo período de afastamento dos estudantes dos bancos escolares se somam às estruturais desigualdades características da sociedade brasileira.

O surgimento da SARs-Cov 2 tem sido discutido por estudos que relacionam a maior pandemia do Século XXI à exploração desenfreada dos recursos naturais e ao desmatamento que se refletem nas alterações observadas na biodiversidade do planeta. Nessa direção, o economista francês, Salama (2021), assinala que animais selvagens portadores do vírus, quando expulsos de seus habitats, entram em contato com outros animais consumidos por humanos ocasionando cadeias de transmissão que tendem a se agravar caso não haja mudança na relação do homem com a natureza.

Com base em alertas da comunidade científica, David Quammen, repórter e divulgador de estudos sobre infecções de origem animal em humanos, apontou a possibilidade de uma pandemia global no livro Spillover: Animal Infections and the Next Human Pandemic, publicado em 2012. Na obra, lançada no Brasil em 2020, sob o título Contágio, o autor explica o principal motivo da atual crise sanitária:

Invadimos florestas tropicais e outras paisagens selvagens, que abrigam tantas espécies de animais e plantas - e dentro dessas criaturas, tantos vírus desconhecidos. Cortamos as árvores; matamos os animais ou os engaiolamos e os enviamos aos mercados. Destruímos os ecossistemas e liberamos os vírus de seus hospedeiros naturais. Quando isso acontece, eles precisam de um novo hospedeiro. Muitas vezes, somos nós. (Quammen, 2020, p. 6).

A declaração da pandemia do novo coronavírus pela Organização Mundial da Saúde (OMS), em 11 de abril de 2020, não foi surpresa para Quammen. Em entrevista publicada no Jornal El País Brasil (Bassets, 2020), o jornalista afirmou que "A

\footnotetext{
${ }^{1}$ Projeto de pesquisa Políticas e estratégias dos sistemas municipais de ensino do ABC Paulista durante a pandemia de Covid-19 (Rosa et al., 2020)
} 
ciência sabia o que ia ocorrer. Os Governos sabiam que podia ocorrer, mas não se preocuparam em se preparar" a despeito dos riscos e da velocidade de propagação do vírus num mundo hiperconectado.

Ocorre que a pandemia chegou em momento especialmente conturbado, de disputa entre as duas maiores economias mundiais (Estados Unidos e China), agravado por condutas irracionais de governos populistas, como o do então presidente norteamericano, Donald Trump, e do brasileiro, Jair Bolsonaro. Salama (2021) sublinha que a crise econômica mundial não se originou da atual crise sanitária, mas a pandemia provocou o agravamento das já difíceis condições de vida de amplos segmentos da população pelo aumento dos níveis de desemprego que afetou principalmente os países periféricos do sistema capitalista.

No caso da América Latina, países como a Venezuela, Argentina e, em menor escala, o México, já enfrentavam dificuldades, enquanto o Brasil tentava se recuperar da grave crise econômica e política de 2015-2016. O contexto dos países latino-americanos, de lento crescimento, baixos investimentos, desigualdades sociais estruturais e condições sanitárias precárias, evidenciou a debilidade política, econômica e social da região.

Paralelamente, a Covid-19 acelerou mudanças que já estavam em curso no mundo do trabalho e nas relações sociais delas decorrentes, em função da ampliação de atividades laborais realizadas em casa. Conforme registra pesquisa realizada pela Rede de Pesquisa Solidária ${ }^{2}$, essa modalidade de trabalho, que sempre se associou à informalidade, à ausência de direitos e salários mais baixos, "era predominantemente feminino e mais frequente em países pobres, segundo a Organização Internacional do Trabalho (OIT)" (Barbosa et al.,2020, p. 2).

$\mathrm{Na}$ pandemia, invertendo a tendência anterior, os autônomos perfaziam menos de $15 \%$ das pessoas que passaram a trabalhar em casa. Em outros termos, 0 teletrabalho atingiu principalmente os profissionais com ensino superior e com vínculo empregatício. Em maio de 2019, os professores representavam $19 \%$ do total de profissionais que estavam trabalhando remotamente, segundo dados PNAD-Covid (Barbosa et al., 2020, p. 4).

Com o fechamento das escolas, em março de 2020, os profissionais da educação básica engrossaram esse contingente. Para dimensionar o que isso significa, de acordo com o Censo Escolar de 2019 (Brasil, 2019), o Brasil possuía 47.874.246 estudantes, 2.212.018 docentes e 248.396 auxiliares docentes, perfazendo mais de 50 milhões de pessoas envolvidas nas relações de ensino e de aprendizagem.

Em 28 de abril de 2020, o Conselho Nacional de Educação aprovou Parecer n. 5/2020 que dispôs sobre a reorganização dos calendários escolares e as atividades pedagógicas não presenciais durante o período de pandemia da Covid-19, em sistemas e unidades escolares estaduais, municipais e particulares de todo o país. Entidades, pesquisadores e profissionais da área (Anped, 2020; Uncme, 2020) criticaram a ausência de orientações e diretrizes claras sobre o ensino remoto, assim como a falta de diálogo do Ministério da Educação com os profissionais da educação e demais

\footnotetext{
${ }^{2} \mathrm{~A}$ Rede de Pesquisa Solidária é uma rede multidisciplinar e multi-institucional, que congrega pesquisadores brasileiros e estrangeiros das áreas de Humanidades, exatas e Biológicas, com o objetivo de colaborar e aperfeiçoar as políticas públicas em meio à crise da Covid-19.
} 
atores sociais envolvidos, uma vez que os problemas causados pela pandemia não se restringem ao calendário escolar, mas impactam dimensões sociais e econômicas que atingem famílias e/ou responsáveis pelos estudantes.

No estado de São Paulo, a Resolução SEDUC, de 18-3-2020, da Secretaria de Estado da Educação regulamentou as atividades remotas, mas restringiu a autorização do teletrabalho (home office) aos profissionais de educação com idade igual ou superior a 60 anos, gestantes e portadores de outras comorbidades ${ }^{3}$. No entanto, pelo pacto federativo brasileiro, cabe aos municípios a decisão de manter o ensino presencial ou remoto, em função da situação sanitária de cada região, o que tem ampliado, consideravelmente, a indefinição de orientações e de estabelecimento de políticas integradas entre a esfera estadual e municipal.

Em Nota Técnica, publicada em maio de 2020, a Campanha Nacional Pelo Direito à Educação ${ }^{4}$ alertou para "diversas situações potencialmente atentatórias ao direito à educação básica, obrigatória", desde que as medidas de atividades pedagógicas não presenciais foram adotadas. O documento chamou especial atenção para a "Exclusão de estudantes e de professores e professoras das 'atividades não presenciais' por falta de acesso a Tecnologias Digitais da Informação e da Comunicação (TDICs)", e apontou a necessidade de "monitorar as políticas públicas emergenciais [...] para identificar práticas e medidas discriminatórias eventualmente decorrentes do caráter experimental dessas políticas (Cnde, 2020, p. 4-7).

Com o isolamento social, os profissionais de educação se defrontaram com grandes limitações do teletrabalho, considerando, principalmente, os níveis de exclusão digital no Brasil. De acordo com dados do Comitê Gestor da Internet no Brasil, em 2019, a disponibilidade de recursos tecnológicos para estudantes era um problema ainda a ser superado:

Em 26\% das escolas urbanas não havia nenhum computador disponível para uso dos alunos em atividades educacionais. Em 92\% das escolas com acesso à Internet havia rede WiFi, porém, em diversas escolas o acesso dos alunos era limitado. Entre as escolas públicas, $90 \%$ tinham WiFi, sendo que um terço (34\%) disponibilizava o acesso para os alunos. Entre as escolas particulares, $96 \%$ possuíam acesso à rede WiFi e $49 \%$ disponibilizavam o acesso para os alunos (CGI.br, 2020, p. 24).

Essa situação não é muito diferente da que ocorre em outros países. A Organização das Nações Unidas (ONU) estima que 46\% da população mundial não tem acesso à internet (Brown, 2020), razão pela qual a ampliação das redes de conexão e a distribuição de dispositivos pelos poderes públicos foram recomendadas pela Unesco como uma das principais estratégias para viabilizar a continuidade das atividades pedagógicas e administrativas das escolas durante o período emergencial.

NoBrasil, iniciativas como essas têm sido implementadas de modo razoavelmente satisfatório em escolas privadas, enquanto estudantes, professores e gestores das redes públicas de ensino, responsáveis por mais de $80 \%$ das matrículas na educação básica, enfrentam dificuldades, muitas delas intransponíveis, para realizar atividades

\footnotetext{
${ }^{3}$ Resolução SE n 26, de 18-3-2020. Recuperado em https://bit.ly/2WeAQVh

${ }^{4}$ Desde a sua criação em 1999, a Campanha Nacional pelo Direito à Educação congrega diferentes grupos e entidades representativas da sociedade civil da área de Educação, com o objetivo de mobilizar forças políticas e de comunicação social, em defesa e promoção dos direitos educacionais no Brasil.
} 
escolares de forma remota. Em um cenário de tantas incertezas, um dos efeitos mais previsíveis da pandemia é que ela aumentará ainda mais a distância entre ricos e pobres no que diz respeito às oportunidades educacionais.

Diante desse quadro, o intuito deste trabalho é contribuir com o esforço empreendido por pesquisadores de outras instituições brasileiras (Fundação Carlos Chagas, 2020; 2020; Confederação Nacional dos Trabalhadores em Educação, 2020; Ferraz, 2020), com vistas conhecer o cenário em que os sistemas públicos de ensino têm enfrentado os inúmeros desafios desse período emergencial. Este estudo traz, especificamente, as percepções de equipes gestoras acerca das estratégias adotadas pelos Sistemas Municipais de Ensino da Região Metropolitana do ABC de São Paulo/ Brasil, nos primeiros meses que se seguiram ao fechamento das escolas. O tratamento dos dados iniciais foi estritamente descritivo/interpretativo, em busca de indicadores a serem aprofundados na etapa qualitativa do estudo à luz de referenciais teóricos do modelo botton-up de implementação de políticas (Ball, Maguire \& Braun, 2012; Passone, 2013), que valorizam a cultura, os valores e a subjetividades dos atores diretamente envolvidos em contextos da prática.

\section{Contexto e metodologia da pesquisa}

O Grande ABC Paulista é uma das cinco sub-regiões da Região Metropolitana de São Paulo, composta por 39 municípios e 21.138.247 habitantes (Fundação Seade, 2020). Localizada à sudeste da capital do estado de São Paulo, essa região é composta por 7 municípios: Diadema, Mauá, Ribeirão Pires, Santo André, Rio Grande da Serra, Santo André, São Bernardo do Campo e São Caetano do Sul, onde vivem 2.690.590 pessoas (Tabela 1 ).

Tabela 1. População da Região do Grande ABC Paulista por Município

\begin{tabular}{lc}
\hline \multicolumn{1}{c}{ Municipio } & Habitantes \\
\hline Diadema & 404.477 \\
Mauá & 460.132 \\
Ribeirão Pires & 118.968 \\
Rio Grande da Serra & 49.816 \\
Santo André & 693.867 \\
São Bernardo do Campo & 812.086 \\
São Caetano do Sul & 151.244 \\
Total & 2.690 .590 \\
\hline
\end{tabular}

Fonte: Fundação Seade, 2020.

Considerada como o berço da indústria automobilística, a região do ABC Paulista, a partir do final dos anos 1990, passou a depender, predominantemente (cerca de $70 \%$ ) do setor de serviços, visto que muitas indústrias migraram para outros estados ou encerraram suas atividades no país. Este foi o caso da Ford, em 2020, após ter fechado sua principal fábrica de caminhões, em São Bernardo do Campo, em 2019. (Reis, 2021).

Ainda assim, em comparação com outras regiões do país, o ABC Paulista desfruta de situação privilegiada, visto que ali se localizam municípios com alto Índice de Desenvolvimento Humano, como é o caso de São Caetano do Sul que, em 2010, 
ostentou $1^{\circ}$ IDHM do país. A soma da riqueza produzida nos sete municípios manteve a região como a quarta mais rica do país, em 2019 , concentrando $1,79 \%$ do Produto Interno Bruto (PIB) nacional (Ferraz, 2019).

Não obstante, a região, que já vinha sendo castigada pela crise econômica brasileira desde 2015, sofreu ainda mais com os fortes impactos da pandemia de Covid-19. A perda de 11.979 postos de trabalho diretos, de janeiro a novembro de 2020 , agravou as desigualdades sociais que se revela na geografia das cidades, nitidamente divididas entre prédios de luxo, residências de classe média e inúmeras favelas.

Em 2020, a pandemia do Covid-19 gerou fortes impactos na saúde e na economia no mundo inteiro. O Grande $A B C$ não fugiu à regra. Desde o começo da pandemia em fevereiro de 2020 até 3/3/2021, o Brasil perdeu mais de 259 mil vidas em razão da doença. No Grande ABC, foram perdidas cerca de 5 mil vidas até o momento. No Brasil, a pandemia adentra 2021 ainda sob a falta de coordenação do governo federal no enfrentamento da doença e o inconcebível atraso da vacinação. (Conceição \& Yamauchi, 2021, p. 11).

No momento da escrita deste texto, os números acima citados eram bem maiores: conforme monitoramento feito pela Universidade John Hopkins em tempo real, o total acumulado de óbitos por Covid-19 no Brasil, em 22 de março de 2021 era de 294.042. No mesmo dia, o número estimado de óbitos nos 5 municípios mais populosos do ABC Paulista ${ }^{5}$, era de 5.951, segundo o Observatório Covid-19BR. Dentre estes, São Caetano do Sul, ironicamente a cidade mais rica da região, contabilizava o maior número de mortes: (302) por 100 mil habitantes (Cardoso \& Fontes, 2021).

No que se refere à educação, no ano anterior à pandemia, os 7 municípios pesquisados contavam com 192.012 alunos matriculados nas diferentes etapas e modalidades da educação básica nas redes públicas municipais (Tabela 2). Vale registrar que, pela legislação brasileira, os municípios são responsáveis pela oferta de vagas na Educação Infantil (creche e pré-escola) e nos cinco primeiros anos do Ensino Fundamental, tanto no ensino regular como nas modalidades de Educação Especial e Educação de Jovens e Adultos (EJA)

Tabela 2. Matrículas por etapa/modalidade de ensino e por município - 2019

\begin{tabular}{|c|c|c|c|c|c|c|c|c|c|c|c|c|}
\hline \multirow{3}{*}{ Município } & \multicolumn{12}{|c|}{$\begin{array}{l}\text { Número de Matrículas na Educação Básica } \\
\text { Etapa de Ensino }\end{array}$} \\
\hline & \multirow{2}{*}{$\begin{array}{c}\text { Total de } \\
\text { Matrículas }\end{array}$} & \multicolumn{3}{|c|}{ Educação Infantil } & \multicolumn{3}{|c|}{ Ensino Fundamental } & \multicolumn{2}{|c|}{ EJA } & \multicolumn{3}{|c|}{ Educação Especial } \\
\hline & & Total & Creche & $\begin{array}{l}\text { Pré- } \\
\text { Escola }\end{array}$ & Total & $\begin{array}{l}\text { Anos } \\
\text { Iniciais }\end{array}$ & $\begin{array}{l}\text { Anos } \\
\text { Finais }\end{array}$ & Total & $\begin{array}{l}\text { Ens. } \\
\text { Fund. }\end{array}$ & Total & $\begin{array}{l}\text { Classes } \\
\text { Comuns }\end{array}$ & $\begin{array}{l}\text { Classes } \\
\text { Exclusivas }\end{array}$ \\
\hline Diadema & 28.359 & 13.377 & 4.061 & 9.316 & 12.536 & 12.513 & 23 & 2446 & 2.446 & 1.087 & 1.046 & 41 \\
\hline Mauá & 18.755 & 14.794 & 6.485 & 8.309 & 2.670 & 2.293 & 377 & 973 & 973 & 318 & 318 & 0 \\
\hline Ribeirão Pires & 7.177 & 4.103 & 1.937 & 2.166 & 3.074 & 2.234 & 840 & 0 & 0 & 143 & 143 & 0 \\
\hline $\begin{array}{l}\text { Rio Grande da } \\
\text { Serra }\end{array}$ & 2.060 & 2.028 & 980 & 1.048 & 0 & 0 & 0 & 32 & 32 & 38 & 38 & 0 \\
\hline Santo André & 37.089 & 17.400 & 7.939 & 9.461 & 17.394 & 17.394 & 0 & 2.295 & 2.295 & 1.058 & 1.058 & 0 \\
\hline $\begin{array}{l}\text { São Bernardo } \\
\text { do Campo }\end{array}$ & 78.353 & 31.280 & 14.075 & 17.205 & 43.646 & 43.611 & 35 & 3.427 & 3.427 & 1.705 & 1.543 & 162 \\
\hline $\begin{array}{l}\text { São Caetano } \\
\text { do Sul }\end{array}$ & 18.219 & 5.470 & 3.063 & 2.407 & 12.094 & 6.713 & 5.381 & 155 & 155 & 500 & 476 & 24 \\
\hline Total & 190.012 & 88.452 & 38.540 & 49.912 & 91.414 & 84.758 & 6656 & 9328 & 9.328 & 4.849 & 4.622 & 227 \\
\hline
\end{tabular}

Fonte: Adaptado pelos pesquisadores - Censo Escolar (Brasil, 2019).

${ }^{5}$ Não há dados disponíveis sobre os municípios de Rio Grande da Serra e Ribeirão Pires. Acessível em: https:// covid19br.github.io/sobre.html 
O atendimento a esses alunos é realizado por 26.705 profissionais de educação, distribuídos entre as 478 unidades escolares, o que representa, em média, 401,7 alunos por escola. Considerando que a infraestrutura das escolas varia conforme a distribuição geográfica da riqueza no interior dos municípios, a razão alunos/escola e alunos/salas de aula não é homogênea. Por consequência, em vista da necessidade de obediência a protocolos comuns de saúde, os desafios para a retomada das aulas presenciais não serão os mesmos em todas as unidades escolares.

Foi neste contexto social e educacional que a primeira etapa deste estudo foi realizada, visando conhecer a percepção dos profissionais de educação sobre as estratégias implementadas pelos sistemas municipais para o ensino remoto. A metodologia adotada foi a de amostragem não-probabilística, com a técnica "bola de neve" (snowball sampling), que busca atingir um coletivo específico via redes de contatos de sujeitos-chave (sementes), selecionados por conveniência.

O tipo de amostragem nomeado como bola de neve é uma forma de amostra não probabilística, que utiliza cadeias de referência. Ou seja, a partir desse tipo específico de amostragem não é possível determinar a probabilidade de seleção de cada participante na pesquisa, mas torna-se útil para estudar determinados grupos difíceis de serem acessado. [...] Isso acontece porque uma amostra probabilística inicial é impossível ou impraticável, e assim as sementes ajudam o pesquisador a iniciar seus contatos e a tatear o grupo a ser pesquisado. (Vinuto, 2014, p. 203)

Essa técnica tornou-se conhecida com o estudo etnográfico Sociedade da Esquina, publicado em 1943, pelo sociólogo norte-americano, William Foote Whyte. Whyte (1914-2000) utilizou o contato inicial de uma assistente social com os moradores de um bairro de imigrantes italianos da cidade de Boston onde estudou as dinâmicas e práticas de contravenção naquela comunidade. "Esse trabalho demonstra a importância de se obter apoio de indivíduos já inseridos no grupo a ser estudado a fim de aumentar a rede de contatos inicial [...] (Vinuto, 2014, p. 205).

Em contextos de difícil acesso ao público-alvo, como o do isolamento social, a técnica "bola de neve" foi a que se mostrou mais viável na primeira etapa do projeto. Professores e gestores das redes municipais, vinculados ao grupo de pesquisa, foram as "sementes" que desencadearam os contatos com a população pretendida no estudo.

A etapa exploratória foi realizada entre os dias de 26 de maio e 10 de junho de 2020, por meio de formulário eletrônico (Google Forms), que atingiu, pelo critério de saturação, 501 respondentes dos 7 municípios. O questionário continha 47 questões fechadas de diferentes modelos (múltipla escolha, caixas de seleção e de escala Likert) e 2 questões abertas onde os respondentes puderam expressar livremente suas preocupações e incertezas frente aos desafios do trabalho remoto.

O instrumento de coleta foi estruturado em quatro eixos de análise: o primeiro reuniu informações sobre o perfil dos sujeitos; o segundo focalizou as estratégias adotadas pelas SME para o ensino remoto; o terceiro procurou identificar a percepção dos respondentes quanto à organização e gestão das escolas e do trabalho pedagógico; o quarto e último eixo procurou captar as principais preocupações e incertezas de docentes e gestores no contexto inicial da pandemia de Covid-19. 
Dos 501 respondentes, 100 (20\%) ocupavam cargos de gestão nas unidades escolares e/ou na esfera dos sistemas. Importante mencionar que, à exceção do município de São Bernardo do Campo, onde o acesso à direção escolar se dá via concurso público, e de Diadema, em que o diretor é eleito pela comunidade, em todos os demais, os diferentes cargos gestão são funções gratificadas temporárias, ocupados por indicação política, como ocorre na maioria dos municípios brasileiros (Drabach \& Adrião, 2017; Souza, 2019). Este fator, potencialmente interveniente nas percepções e opiniões deste grupo, foi levado em conta na interpretação dos dados.

O perfil predominante dos profissionais das redes municipais do ABC Paulista é o de uma mulher (96,1\%) branca $(69,6 \%)$; entre 31 e 50 anos de idade $(68,2 \%)$; com experiência profissional consolidada, acima de 11 anos. 77,9\% são servidores públicos municipais que cumpriam entre 31 e 40 horas ou mais de trabalho semanal $(72,6 \%)$ no momento da coleta dos dados.

Entre os gestores, 33 estavam na direção escolar; 10 na vice-direção; 47 na coordenação pedagógica; 3 na orientação educacional; e 7 desempenhavam a função de supervisores de ensino. Neste segmento, 93\% dos respondentes são mulheres, dado que confirma a esmagadora participação feminina nas atividades educacionais e se relaciona com a intensificação do trabalho apontada por elas durante a pandemia.

\section{Resultados}

O cruzamento das múltiplas variáveis permitiu traçar o cenário, permeado pelos efeitos (perversos) da pandemia, que se refletiu na (des)organização das redes municipais da região ao longo de 2020. A leitura dos dados permitiu a classificação dos resultados nas seguintes categorias exploradas neste artigo: a) estratégias implementadas pelas SME durante o ensino remoto; b) apoio e acolhimento aos sujeitos escolares; c) acompanhamento da aprendizagem e planejamento curricular.

\subsection{Estratégias implementas pelas SME durante o ensino remoto}

No que se refere às estratégias para o ensino remoto, ressalta-se que, três dias após a decretação da pandemia pela OMS, quatro municípios do ABC Paulista (Ribeirão Pires, Santo André, São Bernardo do Campo e São Caetano do Sul) anunciaram a suspensão gradativa das aulas, seguindo orientações da Secretaria Estadual de Educação de São Paulo. Dentre as medidas adotadas pelas secretarias de educação, o recesso escolar $(75,05 \%)$ e a antecipação de férias $(14,17 \%)$ foram as mais mencionadas.

Quanto às atividades realizadas nesse período, 69,29\% disseram que ficaram em casa elaborando materiais; $51,4 \%$ que receberam formação online; e 33\% que fizeram plantões de atendimento nas escolas ${ }^{6}$. De acordo com parte expressiva dos sujeitos (58,7\%), as decisões sobre as estratégias adotadas foram centralizadas nas Secretarias de Educação. A participação de gestores e docentes nos processos de decisão foi apontada, respectivamente, por 43,7\% e 40,1\% da amostra. No entanto, esses índices parecem contraditórios com o que sugerem as informações sobre as ações efetivamente realizadas, como se verá adiante. (Fig. 1)

\footnotetext{
${ }^{6}$ Os índices ultrapassam $100 \%$ pois os mesmos respondentes assinalaram mais de uma alternativa desta questão.
} 
Figura 1. Ensino remoto: planejamento e processos de decisão Durante o período de planejamento do ensino
remoto, houve:

Recesso Escolar

Ficar em casa elaborando materiais

Aguardou em casas para orientações da Secretaria

Formação Online sugerida/oferecida pela

Plantões de Atendimento na escola

Antecipação de Férias
Quanto aos processos de decisão das estratégias de ensino remoto adotadas, houve consulta e participação de:

\begin{tabular}{l}
$75,05 \%$ \\
$69,26 \%$ \\
$59,48 \%$ \\
\hline $51,50 \%$ \\
\hline $33,13 \%$ \\
\hline $14,17 \%$ \\
\hline
\end{tabular}

Foram centralizados na Secretaria de Educação

Gestores Escolares

Docentes

As unidades escolares tiveram autonomia de decisão

Famílias

Conselho Municipal de Educação

Funcionários

Entidades representativas de classe

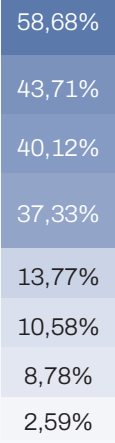

Fonte: Elaborado pelo(as) pesquisador(as).

Mesmo levando em conta que, em situações emergenciais, as decisões tendam a ser tomadas de forma rápida e centralizada, chama a atenção que os percentuais sobre o grau de participação da comunidade escolar nos processos decisórios foram bem mais baixos: a consulta às famílias e funcionários foi mencionada por 22,5\% dos gestores; e às entidades da sociedade civil (Conselho Municipal de Educação, associações, sindicatos, etc.), por apenas 13\%. Esses dados sugerem que o princípio da gestão democrática da educação pública, estabelecido na Constituição Federal de 1988 e na Lei de Diretrizes e Bases da Educação Nacional, de 1996, já tão fragilizado em tempos de normalidade, foi deixado em suspenso durante a pandemia.

Observou-se que os municípios adotaram múltiplas estratégias para o ensino remoto, sendo que as mais citadas foram: envio de atividades pelos docentes por meio digitais (67,6\%); envio de orientações às famílias por meio digitais $(65,8 \%)$; envio/entrega de materiais impressos produzidos pelos docentes da escola (47,5\%); acesso a materiais no site das Secretarias da Educação (45,7\%); uso de aplicativos e/ ou plataformas desenvolvidas pela rede (35,1\%); envio/entrega de material impresso pelas Secretarias de Educação (32,1\%).

Os dados acima evidenciam a contradição apontada anteriormente: embora $58,6 \%$ tenham dito que as secretarias centralizaram os processos decisórios - índice bem maior do que os $37,3 \%$ que afirmaram que as unidades escolares tiveram autonomia - observa-se que, na prática, foram os gestores e docentes os protagonistas das ações efetivamente implementadas. Esta inferência é reforçada pelo fato de que as estratégias menos mencionadas foram: aulas gravadas por outros docentes $(5,19 \%)$ e aulas gravadas em canais de TV $(2,4 \%)$.

No que diz respeito aos recursos (materiais e tecnológicos) utilizados para a comunicação das secretarias com os gestores escolares, chama a atenção que apenas $34 \%$ os consideraram como plenamente adequados; $53 \%$ como parcialmente adequados; e $8 \%$ como inadequados. Esses dados sinalizam que, do ponto de vista das equipes gestoras, a interlocução entre os órgãos centrais e as escolas foi insuficiente. 
Já os recursos para a comunicação dos gestores com os docentes foram considerados plenamente adequados por 33\%; 63\% os consideraram parcialmente adequados, e apenas $4 \%$ os avaliaram como inadequados. Resultados muito semelhantes foram obtidos pela totalidade da amostra, constituída em sua maioria (80\%) por professore(as), o que indica que a integração da equipe gestora com o(as) docentes foi relativamente satisfatória.

Sobre a adequação das estratégias adotadas às especificidades dos alunos em diferentes etapas/modalidades da educação básica, os seguintes índices foram obtidos: Educação Infantil (bebês, 30\%; crianças 2-3 anos, 36\%); Pré-escola (crianças de 4-5 anos, 49\%); Ensino Fundamental (Anos Iniciais, 48\%; Anos Finais, 37\%); Educação de Jovens e Adultos, 39\%. Observou-se, ainda, que a avaliação dos gestores foi ligeiramente mais positiva do que a dos docentes, embora nenhuma das estratégias tenha sido considerada adequada por mais de $50 \%$ dos sujeitos.

Na percepção dos gestores, as estratégias menos adequadas foram as dirigidas aos seguintes segmentos: alunos imigrantes (9\%); alunos em situação de acolhimento institucional/abrigos (10\%); alunos com transtornos funcionais específicos (27\%); alunos da Educação Especial (31\%). Há que se ressaltar que esses alunos são os mesmos que, em tempos de "normalidade", se encontram em situação de maior vulnerabilidade social e psicológica e cujos direitos são os mais ameaçados pelos deletérios efeitos pandemia.

Considerando que os recursos para o processo ensino-aprendizagem na modalidade remota eram elos indispensáveis naquele momento para a conexão dos sistemas de ensino com os alunos, os dados revelam uma situação preocupante: parcela pequena das equipes gestoras (15\%) considerou que os recursos plenamente adequados; a maioria (61\%) os avaliou como parcialmente adequados e $20 \%$ como inadequados. Essa percepção foi corroborada pelos docentes, pois, tomando-se a totalidade da amostra, somente $13,6 \%$ do conjunto da amostra.

\subsection{Apoio e acolhimento aos sujeitos escolares}

No que se refere ao acolhimento aos sujeitos escolares, foram consideradas as ações e iniciativas encetadas pelas diferentes instâncias dos sistemas para atender as necessidades das equipes gestoras, das famílias, dos professores e, sobretudo, dos alunos.

Em relação ao apoio às escolas por parte das secretarias de educação, 54\% dos gestores disseram que estava ocorrendo de forma plenamente satisfatória; 34\%, que estava ocorrendo de forma precária; e 8\% que não estava ocorrendo. Essa avaliação relativamente positiva parece contradizer a que fizeram sobre os recursos de comunicação das secretarias com os gestores. É possível que tal posicionamento se deva ao receio e/ou o constrangimento dos gestores de manifestar críticas a seus superiores hierárquicos. Com efeito, quando se considera o conjunto da amostra (docentes e gestores) os resultados são significativamente diferentes. Somente 32,3\% sentiram que esse apoio foi satisfatório (Gráfico 1). 
Gráfico 1. Apoio aos gestores por parte das Secretarias de Educação

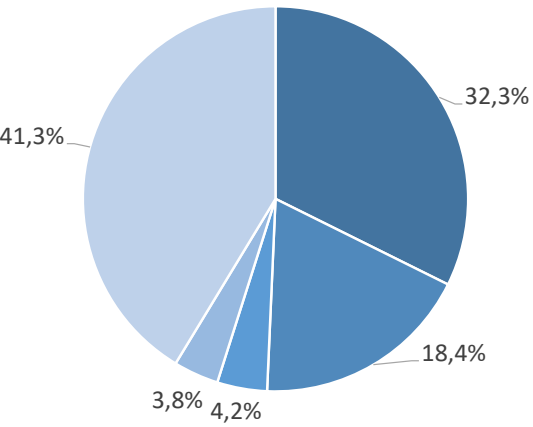

- Está ocorrendo de forma satisfatória = Está ocorrendo de forma precária

- Não está ocorrendo

๒ Prefiro não informar

não Sei

Fonte: Elaborado pelos pesquisadores

Em contraste, o apoio e orientação às famílias por parte das escolas foi avaliado como satisfatório por $63,3 \%$ dos gestores; $24,3 \%$ consideraram que estava ocorrendo de forma precária; e apenas 0,8\% que não estava ocorrendo. Não passou despercebido, porém, o fato de que 7,9\% afirmaram "não saber" e que 3\% preferiram não informar. Este dado é preocupante, dado o relevante papel deste equipamento público para as famílias naquele contexto emergencial.

Já o apoio dado aos docentes pelas equipes gestoras foi bem avaliado: $70 \%$ dos professores disseram que foi satisfatório; 17,9\% que o apoio recebido foi precário, e apenas $2,49 \%$ que não estava ocorrendo. A percepção das equipes gestoras sobre essa questão foi ainda mais positiva: $84 \%$ consideraram que o apoio dado por eles aos docentes estava sendo satisfatório; 15\% reconheceram que estava ocorrendo precariamente; e 1\%, que não estava ocorrendo.

A avaliação majoritariamente positiva dos dois grupos (gestores/docentes) sobre o apoio dado e/ou recebido é coerente com a avaliação de que a organização escolar e a qualidade do trabalho pedagógico não foi significativamente afetada pela pandemia: 38\% consideraram que a rotina das reuniões pedagógicas não foi alterada ou até mesmo que havia melhorado (21,3\%). Contudo, $24,5 \%$ avaliaram que a rotina escolar havia piorado.

Sobre o acolhimento e apoio dos docentes aos alunos, $51 \%$ dos professores consideraram que estava ocorrendo satisfatoriamente; $29 \%$ que estava ocorrendo de forma precária; e 9,7\% que não estava ocorrendo. Na perspectiva dos gestores, a avaliação deste quesito foi mais positiva: 54\% consideraram que estava ocorrendo de modo satisfatório; 34\% que estava ocorrendo precariamente; e $8 \%$ que não estava ocorrendo.

Especificamente em relação aos alunos com deficiências ou transtornos funcionais específicos, $42 \%$ dos gestores disseram que esse apoio estava ocorrendo de forma satisfatória; 31\% que estava ocorrendo de forma precária; e 15\% que não 
estava ocorrendo. Chamou atenção que 7\% disseram não saber e que 5\% preferiram não informar, um índice alto dado que a maioria das escolas possui alunos com deficiências matriculados em salas regulares.

\subsection{Cumprimento do planejamento curricular}

Sob esta categoria, foram reunidas informações que permitem apreender a percepção dos gestores sobre o cumprimento do planejamento curricular e sobre o acompanhamento das atividades e desempenho escolar dos estudantes. Em conjunto, os indicadores mostram que o contexto da pandemia comprometeu o cumprimento do currículo e o direito dos alunos a aprendizagens essenciais. (Gráfico 2).

Gráfico 2. Cumprimento do planejamento curricular (2020)

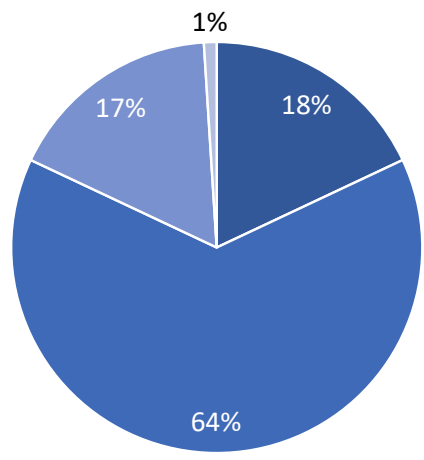

\footnotetext{
- Está sendo cumprido normalmente Está sendo cumprido parcialmente

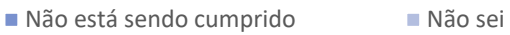

Fonte: Elaborado pelos pesquisadores.

Os dados acima se articulam às dificuldades de acesso e uso das Tecnologias Informação e Comunicação (TICs), tanto por parte dos profissionais como das famílias. Quando indagados se se sentiam angustiados por não saber se os alunos estavam conseguindo acessar a internet e/ou se estavam recebendo as atividades por meios digitais, 68\% manifestaram grande preocupação.

Questionados sobre as dificuldades de comunicação com as famílias e, portanto, com os alunos, 30\% disseram que não estavam tendo muita dificuldade; 37\% admitiram enfrentar alguma dificuldade e 33\% que estavam tendo muita dificuldade. Paralelamente, 30\% dos gestores reconheceram não ter bom domínio dessas ferramentas. Quando se acrescenta a esse contingente os 35\% que admitiram ter domínio relativo das tecnologias, infere-se que a não efetividade do ensino remoto se deve tanto aos problemas de acesso e conexão estável com a internet como à falta de familiaridade do conjunto da comunidade escolar com as TICs.

Outro fator interveniente no cumprimento curricular diz respeito à condição das famílias de acompanhar e orientar os filhos nas atividades escolares em casa. Diante da assertiva "Acredito que as famílias não conseguem ajudar o(a)s filho(as) a realiza- 
rem as atividades escolares", os gestores se mostraram céticos. Os que concordaram total ou parcialmente com essa afirmação representam 46\% da amostra; 39\% não concordaram e nem discordaram; e somente 3\% não manifestaram preocupação.

Mesmo sem dispor de dados sobre a escolaridade das famílias, é fato conhecido que grande parte da população adulta da região possui baixa ou nenhuma escolaridade. Em São Caetano do Sul - cidade com maior IDHM do Brasil -- os chefes de família sem grau de instrução ou com ensino fundamental incompleto representavam 8,9\% da população ${ }^{7}$. Ademais, por serem trabalhadores, que se ocupam prioritariamente com a subsistência de suas famílias, muitos não dispõem de tempo (e/ou paciência) para dar atenção à vida escolar dos filhos, como apontam diversos estudos (Mattos, 2005; Papi, 2015; Martins, Rosa \& Sousa, 2020).

A associação desses fatores com os conflitos familiares intensificados com o isolamento social pode explicar a preocupação manifestada por $87 \%$ dos gestores com a possibilidade de aumento da violência doméstica e outras formas de abuso contra as crianças. Este problema social, cujos impactos educacionais são difíceis de dimensionar, tem sido objeto de atenção de pesquisadores das áreas da saúde e da educação há já algum tempo (Bergamo \& Bazon, 2011; Albuquerque et al.; 2015; Ponce \& Neri, 2018).

Na pandemia, a situação se agravou, sobretudo pela dificuldade de registro de denúncias de estupros de vulneráveis (menores de 14 anos e/ou pessoas com deficiências) em função do isolamento social. Apesar disso, relatório do Ministério Público de São Paulo, em parceria com o Fundo das Nações Unidas para a Infância (UNICEF), mostrou os elevados índices de violência doméstica em 2020:

No primeiro semestre de 2020 , período em que se iniciou a pandemia, a proporção de crimes desse tipo ocorridos em residências do Estado de São Paulo foi de $84 \%$, tendo chegado a $88 \%$ no mês de maio, superando o patamar de $79 \%$ observado ao longo dos anos anteriores. Acometendo em sua maioria crianças, esse crime correspondeu a $75 \%$ do total de estupros registrados no Estado de São Paulo no primeiro trimestre (MPSP, 2020).

Diante de todo esse quadro, a maioria dos gestores (69\%) revelou forte preocupação com o avanço das aprendizagens dos alunos; 19\% demonstraram moderada preocupação e $12 \%$ pareciam menos preocupados com essa questão. Esses resultados são coerentes e parecem correlacionados à percepção de que o acompanhamento do desempenho escolar dos alunos não estava ocorrendo (33\%) ou que estava ocorrendo de forma precária (30\%). Em questão correlata, 66\% dos gestores se diziam preocupados com a possibilidade de aumento dos índices de abandono e evasão escolar.

\section{Discussão}

A leitura integrada dos dados sugere que, não obstante os esforços realizados pelas diferentes instâncias e atores dos sistemas municipais de ensino (gestores públicos, equipe gestora escolar e docentes) para reorganizar e adaptar o trabalho pedagógico às condições emergenciais impostas pela pandemia, as estratégias implementadas não foram suficientes assegurar a eficácia do ensino remoto em uma das regiões mais ricas do País.

\footnotetext{
${ }^{7}$ Dados do Instituto Brasileiro de Geografia e Estatística (Censo de 2010). Recuperado em https://bit.ly/2UymPkV.
} 
Observou-se que não houve - e continua a não haver - ações suficientemente coordenadas por parte dos sistemas de ensino para lidar com as dificuldades que transbordaram para o ano de 2021 com o agravamento da pandemia no país e, particularmente, na região do ABC Paulista. Pelo contrário, os dados indicam que os desafios tendem a se tornar mais complexos com o retorno às atividades escolares presenciais, recaindo diretamente sobre os ombros dos que se encontram na linha de frente: os professores e gestores das unidades de ensino.

No que tange à capacidade dos sistemas para oferecer apoio aos sujeitos escolares, os dados reforçam as preocupações dos profissionais de ensino, especialmente, em relação aos mais vulneráveis: alunos imigrantes, estudantes em situação de abrigo social, pessoas com deficiências e/ou dificuldades de aprendizagem. Na visão das equipes gestoras, estes segmentos foram os mais prejudicados pelas condições precárias em que se deu o ensino remoto.

O fato de quase $70 \%$ dos gestores alegarem dificuldades em estabelecer contato com as famílias, e que $11 \%$ deles sequer sabiam ou preferiram não dar informações a respeito, é especialmente preocupante. Isto porque, além de orientá-las sobre como acompanhar as atividades escolares de seus filhos e fazer a devolutiva aos professores, tal acolhimento incluía oferecer informações confiáveis sobre a doença e formas de prevenir o contágio, realizar a entrega de kits merenda/alimentação e, eventualmente, tomar medidas junto às redes de proteção social em defesa dos direitos dos mais vulneráveis.

Os fatores acima impactaram o cumprimento do planejamento curricular de 2020, comprometendo, por consequência, o desenvolvimento e a aprendizagem dos estudantes. Concorreram para esse cenário as limitações de acesso e conexão estável com a internet, as precárias condições dos adultos de colaborarem com as tarefas escolares, além de dificuldades dos próprios profissionais de lidarem com as ferramentas tecnológicas necessárias ao ensino remoto. Nesse contexto, entende-se por que apenas 18\% dos gestores manifestaram algum otimismo quanto à possibilidade de o ensino remoto mitigar os prejuízos escolares dos que já sofriam o peso das estruturais desigualdades da sociedade brasileira: os alunos das escolas públicas.

Não causa estranheza, portanto, a preocupação manifestada por $82 \%$ dos participantes em relação aos estudantes da modalidade Educação de Jovens e Adultos, cuja escolaridade já fora interrompida e/ou retardada em decorrência de sua condição social pouco privilegiada. Outros segmentos de estudantes também estavam no radar de preocupações desses profissionais: $77,5 \%$ citaram os alunos dos anos iniciais do Ensino Fundamental, cujo processo de alfabetização foi severamente prejudicado; e 33\% mencionaram as crianças em idade pré-escolar que, longe da escola, veem restringidas as possibilidades de socialização e de participação de atividades lúdicas tão necessárias ao desenvolvimento de habilidades físicas, cognitivas e emocionais nessa fase da infância.

\section{Considerações possíveis}

Os dados apresentados neste artigo evidenciam as (in)definições e desdobramento das ações e estratégias adotadas pelas Secretarias Municipais de Educação, realizadas na base de ensaio e erro, após o fechamento das escolas. Apontam, so- 
bretudo, para os prováveis equívocos de elaboração de materiais e da utilização de recursos pouco adequados às especificidades dos alunos. As consequências seguramente foram mais graves para os estudantes em situação de maior vulnerabilidade que pertencem às classes socialmente menos privilegiadas da população brasileira.

No cenário da crise sanitária que ainda perdura, a intensificação do uso de tecnologias no processo de ensino e de aprendizagem revelou, por outro lado, o valor da escola como espaço de socialização e aprendizagem, e dos professores como mediadores de um bem público e direito de todos (a educação), como bem destacou Cury (2020), em ensaio recente. No caso brasileiro, o ensino remoto expôs as limitações de acesso e uso das TICs por parte dos profissionais da educação, das famílias e dos estudantes da escola pública. Tais limitações têm sido apontadas como um dos grandes entraves que as escolas vêm enfrentando para implementar atividades pedagógicas e buscar inovações nas metodologias de ensino.

Em meio a condições tão adversas, os profissionais de educação foram submetidos à severa intensificação de jornada de trabalho, uma vez que não foram estabelecidas "[...] fronteiras claras entre tempo de trabalho, pausas e tempo de descanso."(Barbosa et al 2020,p.14). De acordo com a pesquisa da Rede de Pesquisa Solidária,

As consequências dessa penumbra regulatória são maiores cargas horárias, período de descanso reduzido e falta de compensação por horas extras. Esse quadro já era existente antes mesmo da pandemia - e não foi equacionado pela Reforma Trabalhista de 2017", no Brasil (Barbosa et al., 2020, p. 14).

Ademais, ficou evidenciado que, diante da dispersão de iniciativas das secretarias municipais de educação, as escolas foram chamadas a exercer a autonomia prevista no escopo legal, mas que, em situação de normalidade, nem sempre era efetivada. Vale destacar que a ausência de interlocução entre as diferentes esferas de governo durante a pandemia - federal, estadual e municipal - acentuou o problema historicamente consagrado no campo da política brasileira, qual seja, a não regulamentação do pacto federativo previsto na Constituição Brasileira de 1988.

A falta de sintonia entre as ações governamentais, desde o início da crise sanitária, engendrou inúmeros e sérios problemas, pois as esferas subnacionais de governo assumiram encargos no enfrentamento da pandemia de maneira descoordenada e diferenciada entre as regiões. As estratégias e ações implementadas pelos municípios estudados se enquadram nesse cenário de tentativas de acerto e erro, sem diretrizes claras definidas pela esfera federal e à mercê da sobreposição de medidas legais e normativas preconizadas pelo governo do estado de São Paulo.

Muitos elos indispensáveis ao desenvolvimento e à educação integral dos estudantes brasileiros certamente foram rompidos por conta do isolamento social, da falta de acesso e/ou domínio dos alunos e famílias às tecnologias de comunicação e informação (TIC), da intensificação do trabalho dos profissionais de educação e da dificuldade - e, em muitos casos, da impossibilidade - de superarem as limitações inerentes ao ensino remoto para concretizar o ato educativo. Esse cenário, que tende a aprofundar as desigualdades sociais e educacionais, característicos da sociedade brasileira, explica e justifica as preocupações e incertezas manifestadas pelos respondentes da pesquisa. 
Os reais prejuízos são ainda desconhecidos, mas seguramente serão maiores para os que frequentam as escolas públicas. O longo período de isolamento social, que transbordou para o ano de 2021, com o agravamento da pandemia no Brasil, tende a tornar ainda mais desafiador o processo de retomada da "normalidade" da vida nas escolas. Quando isso ocorrer, alunos, professores e gestores não serão os mesmos que, em meados de março de 2020, tiveram que se dispersar às pressas por causa de um inimigo invisível, pois este terá deixado em todos as marcas do luto, do sofrimento e do cansaço resultantes de uma tragédia anunciada pela ciência, mas desprezada pelos responsáveis pela administração da coisa pública.

\section{Referências}

Albuquerque, L. M; Carvalho, C. M. G.; Apostólico, M. R.; Sakata, K. N.; Cubas, M. R. \& Egry, E. Y. (2015). Terminologia da Enfermagem caracterizadora da violência doméstica contra crianças e adolescentes. Revista Brasileira de Enfermagem, 68(3), 452-459. https://doi. org/10.1590/0034-7167.2015680311i

ANPED (2020). Posicionamento sobre o Parecer do CNE que trata da Reorganização dos Calendários Escolares durante a pandemia. Associação Nacional de Pós-Graduação e Pesquisa em Educação. Recuperado de https://bit.ly/3wXRS6v

Ball, S.J., Maguire, M. \& Braun, A. (2012). How Schools do Policy: policy enactments in secondary schools. London and New York: Routledge.

Barbosa, J., Prates, I., Senne, F., Lins, L. \& Meirelles, T. (2020). Crise altera o perfil do trabalho em casa e do teletrabalho. Desigualdade digital reduz rendimentos e rebaixa atividade econômica. [Nota Técnica No. 16]. Rede de Pesquisa Solidária Recuperado de https:// redepesquisasolidaria.org

Bassets, M. (2020). David Quammen: Os humanos somos mais numerosos do que qualquer outro grande animal. Em algum momento haverá uma correção. Brasil: El País. Recuperado de https://bit.ly/3iHKIUm

Bergamo, L. P. D. \& Bazon, M. R. (2011). Experiências infantis e risco de abuso físico: mecanismos envolvidos na repetição da violência. Psicologia: Reflexão e Crítica, 24(4), 710-719: https:// doi.org/10.1590/S0102-79722011000400011

Brasil (2019). Sinopses Estatísticas da Educação Básica-2019. Brasília, DF: MEC/INEP. Recuperado de https://bit.ly/3zsOtyu

Brown, D. (2021). Closing the 'Digital Divide' Critical in Covid-19 Response. Human Rights Watch. Recuperado de https://bit.ly/2V6WwC2

Cnde (2020). Recomendação para a disponibilização e a coleta de dados sobre as ações das redes de ensino relacionadas às atividades educacionais durante a pandemia de Covid-19 [Nota Técnica]. Campanha Nacional pelo Direito à Educação. São Paulo/Fortaleza: Cnde/ Cedeca-CE/Diepee-Ufabc/Repu. Recuperado de https://bit.ly/3BIdrfh

Cardoso, W. \& Fontes, R. (2021). São Caetano lidera ranking de mortes por 100 mil habitantes na Grande SP. Folha de São Paulo. Recuperado de https://bit.ly/3zkcyr8

CGI.br (2020). TIC Educação: Pesquisa sobre o uso das tecnologias de informação e comunicação nas escolas brasileiras - 2019. São Paulo: Comitê Gestor da Internet no Brasil. Recuperado de https://bit.ly/3l21ivN

Conceição, J.J \& Yamauchi, G. (2021). A Região do Grande ABC Paulista e o tombo de R\$ 5,6 bi em "W" em 2020. Conceição, J.J. da; Ferreira, A.P.L. Carta de Conjuntura da USCS (Ed.16). São Caetano do Sul: Conjuscs, USCS. Recuperado de https://www.uscs.edu.br/boletim/471

Cury, C.J. (2020). Educação escolar e pandemia. Pedagogia em Ação, 13(1), 8-16. Recuperado de http://200.229.32.43/index.php/pedagogiacao/article/view/23749 
Drabach, N. \& Adrião, T. A seleção de dirigentes escolares no Brasil: oscilações entre diferentes estratégias (2017). Jornal de Políticas Educacionais, 11(8), 1-19. http://dx.doi.org/10.5380/ jpe.v11i0.49788

Ferraz, S. (2019). PIB da região segue como o quarto do País. Santo André: Diário do Grande ABC. Recuperado de https://bit.ly/3iONO1c

Ferraz, M. (2020). Políticas Educacionais e as novas invenções de controle sobre a organização do trabalho dos profissionais de educação no cenário da pandemia da Covid-19: o caso do Paraná. [Projeto de Pesquisa]. Universidade Federal do Paraná.

Fundação Carlos Chagas. (2020). Educação escolar em tempos de pandemia na visão de professoras/ es da Educação Básica. [Informen.1] São Paulo: FCC. Recuperado de https://bit.ly/3eKITk4

Fundação Seade (2020). Informações dos municípios paulistas. Recuperado de http://www.imp. seade.gov.br/frontend/\#/

Gestrado/UFMG (2020). Trabalho docente em tempos de pandemia. [Relatório Técnico] Belo Horizonte, MG: Grupo de Estudos sobre Políticas e Trabalho Docente/Confederação Nacional dos Trabalhadores em Educação (CNTE). Recuperado de https://bit.ly/3x1l1Nh

Martins, A. M., Rosa, S.S. \& Sousa, S.M.Z.L. (2020). Alocação de alunos por turmas em rede municipal de ensino: percepções de diretores escolares. Revista Brasileira de Política eAdministração da Educação, 36(3), 1153-1175. https://doi.org/10.21573/vol36n32020.101037

Mattos, C. L.G. (2005). O conselho de classe e a construção do fracasso escolar. Educação e Pesquisa, 31(2), 215-228. https://doi.org/10.1590/S1517-97022005000200005.

Ministério Público do Estado de São Paulo (2020). Análise das ocorrências de estupro de vulnerável no Estado de São Paulo. Recuperado de https://bit.ly/estuprosvulneráveis

Quammen, D. (2020). Contágio: Infecções de origem animal e a evolução das pandemias [Ed. Kindle]. São Paulo: Companhia das Letras.

Papi, S.O.G. (2015). Conselho de classe: que colegiado é esse? Estudos em Avaliação Educacional, 26(62), 480-518. https://doi.org/10.18222/eae266202931

Passone, E. (2013). Contribuições atuais sobre o estudo de implementação de políticas educacionais. Cadernos de Pesquisa, 43(149), 596-615. https://doi.org/10.1590/S010015742013000200011

Ponce, B.J. \& Neri, F. O. N. (2018). Violência contra a criança, educação em direitos humanos e justiça curricular. Revista InterAção, 43(2), 360-377. DOI: https://doi.org/10.5216/ia.v43i2.52511

Reis, A. (2021). Ford anuncia fim da produção de veículos no Brasil e fechamento de fábricas. São Paulo, UOL. Recuperado em https://bit.ly/2UFivAc

Rosa, S.S., Pereira, R., Aparício, A.S.M., Martins, A.M., Ponce, B.J. \& Silva, M.R.P. (2020). Políticas e Estratégias dos Sistemas Municipais de Ensino do ABC Paulista durante a pandemia de Covid-19 [Relatório de Pesquisa] Recuperado de https://www.uscs.edu.br/boletim/338

Salama, P. (2021). Contagio viral, contagio económico: riesgos poíticos en América Latina. Buenos Aires: Clacso; Montevideo; Alas. Recuperado de https://bit.ly/3hXIPyg

São Paulo (2020). Resolução SEDUC, de 18-3-2020. Secretaria do Estado de Educação de São Paulo. Recuperado de https://bit.ly/3ilK43p

Souza, A.R. (2019). As condições de democratização da gestão da escola pública brasileira. Ensaio: aval. pol. públ. Educ., 27(103), 271-290. https://doi.org/10.1590/S0104-40362018002601470

Vinuto, J. (2014). A amostragem em bola de neve na pesquisa qualitativa: um debate em aberto. Temáticas, 22(44), 203-220. https://doi.org/10.20396/tematicas.v22i44.10977

UNCME (2020). Educação em tempos de pandemia: direitos, normatização e controle social. Um guia para os Conselheiros Municipais de Educação. União Nacional dos Conselhos Municipais de Educação.UNCME/UNICEF. Recuperado de https://bit.ly/3wYri19

Como citar este artículo en APA:

Da Rosa, S. S. \& Martins, A. M. (2021). Ensino remoto em sistemas municipais de educação no Brasil: percepções dos gestores escolares. Revista Ibero-americana de Educação, 86(2), 77-93. https://doi.org/10.35362/rie8624380 